\title{
Polycyclic aromatic hydrocarbons, polychlorinated biphenyls, and chlorinated pesticides in background air in central Europe - investigating parameters affecting wet scavenging of polycyclic aromatic hydrocarbons
}

\author{
P. Shahpoury ${ }^{1}$, G. Lammel ${ }^{1,2}$, A. Holubová Šmejkalováa ${ }^{3,4}$, J. Klánová ${ }^{2}$, P. Přibylová ${ }^{2}$, and M. Váňa \\ ${ }^{1}$ Max Planck Institute for Chemistry, Mainz, Germany \\ ${ }^{2}$ Research Centre for Toxic Compounds in the Environment, Masaryk University, Brno, Czech Republic \\ ${ }^{3}$ Czech Hydrometeorological Institute, Košetice, Czech Republic \\ ${ }^{4}$ Global Change Research Centre, Academy of Sciences of the Czech Republic, Prague, Czech Republic
}

Correspondence to: G. Lammel (g.lammel@mpic.de) and P. Shahpoury (p.shahpoury@mpic.de)

Received: 13 September 2014 - Published in Atmos. Chem. Phys. Discuss.: 28 October 2014

Revised: 25 December 2014 - Accepted: 6 January 2015 - Published: 19 February 2015

\begin{abstract}
Concentrations of polycyclic aromatic hydrocarbons (PAHs), polychlorinated biphenyls (PCBs), and chlorinated pesticides (CPs) were measured in air and precipitation at a background site in central Europe. $\sum \mathrm{PAH}$ concentrations in air and rainwater ranged from 0.7 to $327.9 \mathrm{ng} \mathrm{m}^{-3}$ and below limit of quantification (<LOQ) to $2.1 \times 10^{3} \mathrm{ng} \mathrm{L}^{-1}$. The concentrations of PCBs and CPs in rainwater were $<\mathrm{LOQ}$. $\sum \mathrm{PCB}$ and $\sum \mathrm{CP}$ concentrations in air ranged from $<$ LOQ to 44.6 and $<$ LOQ to $351.7 \mathrm{pg} \mathrm{m}^{-3}$, respectively. The potential relationships between PAH wet scavenging and particulate matter and rainwater properties were investigated. The concentrations of ionic species in particulate matter and rainwater were significantly correlated, highlighting the importance of particle scavenging process. Overall, higher scavenging efficiencies were found for relatively less volatile PAHs, underlining the effect of analyte gas-particle partitioning on scavenging process. The particulate matter removal by rain, and consequently PAH wet scavenging, was more effective when the concentrations of ionic species were high. In addition, the elemental and organic carbon contents of the particulate matter were found to influence the PAH scavenging.
\end{abstract}

\section{Introduction}

Semi-volatile organic compounds (SOCs), such as polycyclic aromatic hydrocarbons (PAHs), polychlorinated biphenyls (PCBs), and chlorinated pesticides (CPs), can reach remote and background regions through atmospheric transport and deposition processes (Blais, 2005; Hageman et al., 2006; Grimalt et al., 2001). Wet scavenging is an important mechanism through which atmospheric SOCs enter terrestrial and aquatic ecosystems (van Ry et al., 2002). Nonreactive gaseous SOCs are removed from the atmosphere by gas scavenging process, which is controlled by the SOC equilibrium partitioning with falling raindrops, as described by Henry's law. In contrast, particle-associated species are removed from the atmosphere mainly through particle scavenging (Ligocki et al., 1985), a process controlled by physical parameters including particulate matter (PM) characteristics, cloud microphysics, and meteorological conditions (Poster and Baker, 1996). Therefore, factors that affect SOC gas-particle partitioning, such as ambient temperature, relative humidity, PM chemical composition and surface characteristics, and SOC vapor pressure (Lohmann and Lammel, 2004), may play an important role in determining the relative contributions of gas and particle scavenging processes. It was suggested that SOC scavenging efficiencies would be between 1-3 orders of magnitude higher in case of in-cloud scavenging compared to that of below-cloud scavenging (Ligocki et al., 1985). Poten- 
tial variability in scavenging efficiencies has also been suggested between rain events originated from warm and cold clouds (Bidleman, 1988). A number of studies observed variations in scavenging efficiencies of SOCs between different precipitation events (Offenberg and Baker, 2002; Agrell et al., 2002; Liu et al., 2013; Kaupp and McLachlan, 2000; McLachlan and Sellström, 2009; Atlas and Giam, 1988). To this date, studies have mainly focused on determining the relative importance of SOC gas and particle scavenging processes. However, to the best of our knowledge, no comprehensive study has been conducted to understand the causes behind the variability in scavenging efficiencies. Therefore, in this study we aimed at filling this gap by investigating the relationships between a set of aerosol and rainwater properties and SOC scavenging. The present study was conducted at a background site in central Europe, as a follow up to a previously published research (Škrdlíková et al., 2011) in which PAH scavenging efficiencies were determined at that site. The specific objectives of the present study were to (1) measure the concentrations of PAHs, PCBs, and CPs in air and rainwater samples, (2) estimate wet depositional fluxes of target compounds in the study area, (3) determine wet scavenging efficiencies and scavenged mass fractions of the analytes, and (4) investigate the potential relationships between analyte scavenging and meteorological parameters as well as aerosol and rain characteristics. PAHs, PCBs, and CPs were selected because they are widespread atmospheric contaminants and have been found in air at background locations across Europe (Dvorská et al., 2009; Gioia et al., 2007; Roots et al., 2010; Halse et al., 2011). In addition, these chemicals can persist in the environment due to their resistance to photolytic, chemical, and biological degradation (Yolsal et al., 2014).

\section{Experimental}

\subsection{Sampling site}

The sampling was conducted at the Košetice observatory located in an open land about $70 \mathrm{~km}$ southeast of Prague in the Czech Republic (Fig. S1 in the Supplement). The observatory is classified as a European background site (Dvorská et al., 2008). It is managed by the Czech Hydrometeorological Institute (CHMI) and is part of the European Monitoring and Evaluation Program. The area is covered with snow 2-3 months per year with the mean annual temperature and precipitation of $7.1^{\circ} \mathrm{C}$ and $625 \mathrm{~mm}$. The potential source of pollution in the region is the nearby highway $(\sim 7 \mathrm{~km}$ west of the observatory) connecting Prague to Brno. In addition, due to having dominant westerly winds, atmospherically transported contaminants from the industrial and urban areas of the Czech Republic, notably Prague, may contribute to the pollution in the area.

\subsection{Sampling procedure}

Rainwater and air samples were collected during the period of December 2011 to January 2014 (Table S1 in the Supplement). A total of 231 rain samples were collected using an automatic precipitation sampler (Baghira, Czech Republic) equipped with a $1 \mathrm{~m}^{2}$ stainless steel collection funnel, a lid, and a $5 \mathrm{~L}$ glass collection bottle. The opening and closing of the lid is triggered by a precipitation sensor mounted on the sampler. During sampling, rain drains from the funnel and accumulates in the collection bottle. The collected sample volumes were between 0.5 and $1 \mathrm{~L}$, depending on the amount of rainfall for each event. Larger or smaller volumes were discarded - the latter was not deemed to provide enough analyte mass for trace analysis.

Air samples were collected on quartz fiber filters (QFF) (Grade QM-A, $10.1 \mathrm{~cm}$ inner diameter (ID), Whatman, UK) and in polyurethane foam (PUF) plugs $(5.5 \mathrm{~cm} \mathrm{ID,} 5 \mathrm{~cm}$ height, Organika, Poland) using a Graseby Andersen PS1 high-volume sampler (GA, USA) with a flow rate of $17 \mathrm{~m}^{3} \mathrm{~h}^{-1}$. For each sampling period, two consecutive PUF plugs and one filter paper were deployed. A total of 162 gas and particulate phase air samples were collected during the period of study. Nevertheless, only samples from 54 events were considered for determining scavenging parameters because only these were followed by rain events. The collection of these samples started between 6 and $35 \mathrm{~h}$ prior to the onset of rain (predicted by CHMI) and stopped when rainfall started (Table S2). This sampling approach was chosen in order to sample rainwater from the same air mass as that of PM. In addition, PM has been suggested to be removed from a traveling air parcel by up to 8 and $23 \%$ in the first 24 and $72 \mathrm{~h}$ after the onset of rain, respectively (Wiman et al., 1990; Škrdlíková et al., 2011). This means that prolonging the air sampling beyond the onset of rain would potentially lead to underestimating contaminant concentrations in air and, therefore, overestimating scavenging efficiencies and washed-out mass fractions. In addition, relative humidity substantially increases during rainfall and this would potentially affect gas-particle partitioning of SOCs in the air leading to underestimation or overestimation of gaseous and particulate fraction of contaminants.

Field blanks for air samples were prepared at the site following the standard protocol for mounting QFF and PUF plugs onto the sampler without turning on the sampler. No field blanks were generated for rain samples.

\subsection{Meteorological and other supporting data}

Cloud top heights were estimated from radiosonde measurements over Prague (Station No. 11520) (IGRA, 2014) (Table S2). Meteorological parameters - i.e., near-ground temperature, precipitation type and intensity, cloud base heights (determined through on-site ceilometer measurements), concentrations of $\mathrm{PM}_{2.5}$ and $\mathrm{PM}_{10}$, and their ionic species (i.e., 
$\mathrm{SO}_{4}^{2-}, \mathrm{NO}_{3}^{-}$, and $\mathrm{NH}_{4}^{+}$), elemental carbon (EC), and organic carbon (OC) contents - were obtained from CHMI (Table S3). Aerosol number size distribution data, used for calculating the aerosol surface concentrations, was obtained from the Academy of Sciences of the Czech Republic. Analyte physico-chemical properties were obtained from Estimation Programs Interface Suite 4.11 (USEPA, 2012). The weather charts used to determine the occurrence of frontal passage over the study site were obtained from Berliner Wetterkarte (BWK, 2013).

\subsection{Chemical analysis and quality control}

QFF and PUF samples were extracted with dichloromethane using an automatic extraction system (Büchi B-811, Switzerland). PUF plugs $(n=2)$ related to each sampling period were extracted together. Field blanks were extracted along with each set of 10 samples. The extracts were concentrated under a gentle stream of nitrogen in ambient temperature and fractionated using a silica column for PAHs and a sulfuric acid modified silica column for PCBs and CPs. The method performance was tested prior to sample analysis and no degradation of target analytes due to acid treatment was detected. Analytes in rainwater were extracted using solid-phase extraction (C18 Speedisks, Bakerbond, the Netherlands). The analytes were later eluted using $40 \mathrm{~mL}$ of $(1: 1)$ dichloromethane: $n$-hexane, concentrated under a gentle stream of nitrogen, and passed through a glass column packed with anhydrous sodium sulfate ( $1 \mathrm{~cm} \mathrm{ID,} 3 \mathrm{~cm}$ height) to remove residual water. Prior to extraction, all air and rainwater samples and blanks were spiked with a solution containing $\mathrm{d}_{8}$-naphthalene, $\mathrm{d}_{10}$-phenanthrene, $\mathrm{d}_{12}$-perylene, PCB 30, and PCB 185, which were used as recovery standards.

Samples were analyzed for 26 parent PAHs (i.e., naphthalene (NAP), acenaphthylene (ACY), acenaphthene (ACE), fluorene (FLN), phenanthrene (PHE), anthracene (ANT), fluoranthene (FLT), pyrene (PYR), benzo( $a$ )anthracene (BAA), chrysene (CHR), benzo $(b)$ fluoranthene $(\mathrm{BBF})$, benzo $(k)$ fluoranthene (BKF), benzo $(a)$ pyrene (BAP), indeno $(123-c d)$ pyrene (IPY), dibenz $(a, h)$ anthracene (DHA), benzo $(g, h, i)$ perylene (BPE), benzo(b)fluorene (BFN), benzo $(g, h, i)$ fluoranthene (BGF), cyclopenta $(c, d)$ pyrene (CPP), triphenylene (TPH), benzo $(j)$ fluoranthene $(\mathrm{BJF})$, benzo $(e)$ pyrene (BEP), perylene (PER), dibenz $(a, c)$ anthracene (DCA), anthanthrene (ATT), coronene (COR)), one heterocyclic PAH (i.e., benzonaphthothiophene (BNT)), and one alkylated PAH (i.e., retene (RET)) using a HewlettPackard gas chromatograph (GC 6890) interfaced to a Hewlett-Packard mass selective detector (MS 5973). Seven PCBs (i.e., PCB 28, PCB 52, PCB 101, PCB 118, PCB 138, PCB 153, and PCB 180) and 13 CPs, namely $\alpha$ hexachlorocyclohexane $(\mathrm{HCH}), \beta-\mathrm{HCH}, \gamma-\mathrm{HCH}, \delta-\mathrm{HCH}$, $\varepsilon$-HCH, $o, p^{\prime}$-dichlorodiphenyldichloroethylene (DDE), $p, p^{\prime}$-DDE, $o, p^{\prime}$-dichlorodiphenyldichloroethane (DDD), $p, p^{\prime}$-DDD, $o, p^{\prime}$-dichlorodiphenyltrichloroethane (DDT), $p, p^{\prime}$-DDT, pentachlorobenzene (PeCB), hexachlorobenzene (HCB), were analyzed using an Agilent GC (7890) coupled with an Agilent Triple Quadrupole MS/MS (7000B). All analytes were separated on a $\mathrm{J} \& \mathrm{~W}$ Scientific capillary column (HP-5ms, $0.25 \mathrm{~mm}$ ID, $0.25 \mu \mathrm{m}$ film thickness). $\mathrm{d}_{14}{ }^{-}$ $p$-Terphenyl and PCB 121 were used as internal standards for $\mathrm{PAH}$ and $\mathrm{PCB} / \mathrm{CP}$ analysis, respectively. The analytical method recoveries for $\mathrm{PAHs}$ and $\mathrm{PCBs} / \mathrm{CPs}$ ranged from 72 to $102 \%$ and 88 to $100 \%$, respectively. The measured analyte concentrations were not recovery corrected.

Limits of quantification (LOQ) for analytes were calculated based on instrument detection limits, which in turn are determined using 3 times the chromatogram baseline noise level. The median LOQs for individual PAHs and PCBs/CPs in air samples were 0.006 and $0.0005 \mathrm{ng} \mathrm{m}^{-3}$, respectively. The median LOQs in rainwater samples were 0.05 and $0.45 \mathrm{ng} \mathrm{L}^{-1}$, respectively. LOQ values were used in cases where analyte concentrations in field blanks were <LOQ. The mean concentrations of analytes in five field blanks were subtracted from those in the corresponding samples. The concentrations that were lower than the mean +3 standard deviations of those in field blanks were considered < LOQ and were substituted with $\mathrm{LOQ} / 2$ for calculation of averages.

Analysis of ionic species in rainwater was done using a Hewlett-Packard capillary electrophoresis system (HP 3D $\mathrm{CE}$ ). Measurements were performed using an uncoated silica capillary column ( $75 \mu \mathrm{m} \mathrm{ID,} 70 \mathrm{~cm}$ length). The applied separation voltage was $-10 \mathrm{kV}$ with hydrodynamic injection of $50 \mathrm{mbar}, 20 \mathrm{~s}^{\prime}$. Analytes were detected indirectly at $254 \mathrm{~nm}$ wavelength. The electrolyte was composed of $5 \mathrm{mM}$ sodium chromate and boric acid ( $\mathrm{pH} 8.3$ ) and $0.5 \mathrm{mM}$ cetyltrimethylammonium bromide. Quantification was performed using individual calibration curves. Each quantification was performed three times and mean values were used.

\subsection{Calculations and data analysis}

Analyte particulate mass fractions, $\theta$ (unitless), were calculated using Eq. (1),

$\theta=C_{\mathrm{ip}} /\left(C_{\mathrm{ig}}+C_{\mathrm{ip}}\right)$,

where $C_{\text {ip }}$ is analyte $(i)$ air concentration $\left(\mathrm{ng} \mathrm{m}^{-3}\right)$ in particulate phase and $C_{\mathrm{ig}}$ is that in gas phase. Daily wet deposition fluxes, $F_{\text {wet }}\left(\mathrm{ng} \mathrm{m}^{-2}\right)$, were determined using Eq. (2),

$F_{\text {wet }}=C_{\text {ir }} \times P$,

where $C_{\text {ir }}$ is analyte concentration in rainwater $\left(\mathrm{ng} \mathrm{L}^{-1}\right)$ and $P$ is the rain volume received per collection area $\left(\mathrm{L} \mathrm{m}^{-2}\right)$ in each sampling day. Seasonal fluxes were calculated by summing the daily fluxes in each season. Total scavenging ratios, $W_{\mathrm{t}}$ (unitless), were calculated using Eq. (3),

$W_{\mathrm{t}}=\frac{C_{\text {ir }} \times 10^{3}}{\left(C_{\mathrm{ig}}+C_{\mathrm{ip}}\right)}$, 
where multiplication by $10^{3}$ accounts for conversion from $n g \mathrm{~L}^{-1}$ to $\mathrm{ng} \mathrm{m}^{-3}$. The mass fraction of the total analyte burden in air washed out by below- and in-cloud scavenging, $\varepsilon_{\mathrm{t}}$ (unitless), is calculated according to Škrdlíková et al. (2011) using Eq. (4),

$\varepsilon_{\mathrm{t}}=\frac{b_{\mathrm{r}}}{b_{\mathrm{a}}}=\frac{C_{\mathrm{ir}} \times P}{\left(C_{\mathrm{ig}}+C_{\mathrm{ip}}\right) \times h}$,

where $b_{\mathrm{r}}$ and $b_{\mathrm{a}}$ are analyte burdens $\left(\mathrm{ng} \mathrm{m}^{-2}\right)$ in rainwater and air, respectively, and $h(\mathrm{~m})$ is the height of the air column subject to precipitation, which corresponds to the cloud height from which precipitation originates.

\section{Results and Discussion}

\subsection{Concentrations and distribution of analytes}

\subsubsection{Concentrations in air}

NAP was targeted for analysis but it did not pass our quality control criteria and, therefore, is not discussed hereafter. In addition, only analytes that were detected in $>10 \%$ of the samples are discussed herein (Tables 1, 2). $\sum$ PAH (i.e., the sum of $27 \mathrm{PAHs}$ ) concentrations in gas phase ranged from 0.6 to 138.6 (mean \pm standard deviation (SD): $11.3 \pm 15.7) \mathrm{ng} \mathrm{m}^{-3}$ (Table 1). PAHs with molecular mass $<228 \mathrm{Da}$, namely ACY, ACE, FLN, PHE, ANT, FLT, and PYR, were predominant in gas phase and, on average, accounted for $93 \%$ of the $\sum$ PAH concentrations. PHE, FLN, and FLT showed the highest mean contributions accounting for 42,24 , and $12 \%$ of the $\sum$ PAH gaseous concentrations, respectively. BKF, BAP, IPY, DHA, BPE, BNT, CPP, BJF, BEP, PER, DCA, ATT, and COR were detected in $<10 \%$ of the gaseous samples $(n=162)$ (Table 1). The $\sum$ PAH concentrations in the particulate phase ranged from 0.1 to 189.3 (mean \pm SD: $9.3 \pm 21.2$ ) $\mathrm{ng} \mathrm{m}^{-3}$ (Table 1). In sum, PAHs with molecular mass $>228 \mathrm{Da}$ were predominant in particulate phase and, on average, contributed to $67 \%$ of the $\sum$ PAH particulate concentrations. However, FLT and PYR showed the highest individual contributions and, on average, accounted for 13 and $11 \%$ of the $\sum$ PAH concentrations, respectively. The sum of the concentrations of gas and particulate phase PAHs ranged from 0.7 to $327.9 \mathrm{ng} \mathrm{m}^{-3}$, with the mean \pm SD being $20.6 \pm 35.9 \mathrm{ng} \mathrm{m}^{-3}$. The PAH concentration ranges in gas and particulate phase are noticeably higher than those measured by Škrdlíková et al. (2011) (i.e., $0.9-34.6$ and $0.1-16.8 \mathrm{ng} \mathrm{m}^{-3}$, respectively) for samples collected from the same site during the 2007-2008 period, but are slightly lower than those reported by Holoubek et al. (2007) for the period between 1996 and 2005 (i.e., 0.4208 and $0.1-359 \mathrm{ng} \mathrm{m}^{-3}$, respectively).

Except for $p, p^{\prime}$-DDE, the targeted chlorinated compounds were mainly detected in gas phase (i.e., $<10 \%$ in particulate phase) (Table 2). The concentrations of $p, p^{\prime}$-DDE in particulate phase ranged from $\angle \mathrm{LOQ}$ to 6.8 (mean $\pm \mathrm{SD}$ : $0.4 \pm 0.7) \mathrm{pg} \mathrm{m}^{-3}$. In gas phase, $\beta-\mathrm{HCH}, \delta-\mathrm{HCH}, \varepsilon-\mathrm{HCH}$, and $o, p^{\prime}$-DDD were detected in $<10 \%$ of all samples $(n=$ 162). The concentrations in gas phase ranged from $<$ LOQ to 43.5 (mean \pm SD: $8.1 \pm 7.2$ ) $\mathrm{pg} \mathrm{m}^{-3}$ for $\sum$ PCBs (i.e., the sum of the concentrations of PCBs 28, 52, 101, 118, 138,153 , and 180), < LOQ to $73.8(11.0 \pm 11.6) \mathrm{pg} \mathrm{m}^{-3}$ for $\sum$ HCHs (i.e., the sum of the concentrations of $a$ - and $\gamma$ $\mathrm{HCH}),<$ LOQ to $104.3(23.2 \pm 19.8) \mathrm{pg} \mathrm{m}^{-3}$ for $\sum$ DDTs (i.e., the sum of the concentrations of $o, p^{\prime}$-DDE, $p, p^{\prime}$-DDE, $p, p^{\prime}$-DDD, $o, p^{\prime}$-DDT, and $p, p^{\prime}$-DDT) and <LOQ to 332.3 $(96.1 \pm 42.0) \mathrm{pg} \mathrm{m}^{-3}$ for $\sum \mathrm{CBs}$ (i.e., the sum of the concentrations of PeCB and $\mathrm{HCB}$ ) (Table 2). On average, PCB 28 $(40 \%), \gamma$-HCH $(56 \%), p, p^{\prime}$-DDE ( $\left.83 \%\right)$, and HCB $(90 \%)$ predominated $\sum \mathrm{PCB}, \sum \mathrm{HCH}, \sum \mathrm{DDT}$, and $\sum \mathrm{CB}$ concentrations, respectively. The sum of the concentrations of gas and particulate phase PCBs and CPs ranged from $<$ LOQ to 44.6 and < LOQ to $351.7 \mathrm{pg} \mathrm{m}^{-3}$, respectively. The measured concentrations in the present study are considerably lower than those reported by Holoubek et al. (2007) for the samples collected from the same location between 1996 and 2005 (i.e., from $<\mathrm{LOQ}$ to $390 \mathrm{pg} \mathrm{m}^{-3}$ for $\sum \mathrm{PCBs}$, <LOQ to $771 \mathrm{pg} \mathrm{m}^{-3}$ for $\sum \mathrm{HCHs}, 1$ to $207 \mathrm{pg} \mathrm{m}^{-3}$ for $\sum$ DDTs, and $<$ LOQ to $831 \mathrm{pg} \mathrm{m}^{-3}$ for HCB). As production and use of these compounds are banned in Europe, the relatively low concentrations in the present study could indicate emission due to volatilization from contaminated soil around Košetice (Fig. S1). This argument is supported by significant correlations found between the ambient temperature at the sampling site and the measured concentrations of PCB $28(r=$ $0.70, P<0.05, n=162), \gamma-\mathrm{HCH}(r=0.74, P<0.05)$, and $p, p^{\prime}$-DDE $(r=0.71, P<0.05)$. Despite having the highest mean concentration among the other chlorinated analytes, relatively small correlation was found between the concentrations of HCB and ambient temperature changes $(r=0.25)$. This could be due to the fact that this compound has different source pathways compared to all other chlorinated chemicals investigated in this study. Although banned, HCB could potentially be released to the environment as an unintended byproduct of organic solvent and aluminum manufacturing and waste burning (EPER, 2014). In addition, this compound is present in some pesticide formulations, such as chlorothalonil, which is currently registered for use in $\mathrm{Eu}-$ rope.

\subsubsection{Concentrations in rain}

$\sum$ PAH concentrations in rainwater ranged from $<$ LOQ to $2.1 \times 10^{3}$ (mean \pm SD: $\left.173.3 \pm 256.1\right) \mathrm{ng} \mathrm{L}^{-1}$ (Table 3), predominated (mean: $69 \%$ ) by congeners with $<228$ Da molecular mass. FLT, PHE, and PYR showed the highest individual contributions and, on average, accounted for 35, 14, and $10 \%$ of the $\sum$ PAH concentrations. The $\sum$ PAH concentration range in the present study was higher than the one reported by Škrdlíková et al. (2011) for Košetice (i.e., from 7.1 
Table 1. PAH concentrations and detection frequencies (DF) in air $(n=162)$.

\begin{tabular}{|c|c|c|c|c|c|c|c|c|}
\hline & \multicolumn{4}{|c|}{ Gaseous concentrations $\left(\mathrm{ng} \mathrm{m}^{-3}\right)$} & \multicolumn{4}{|c|}{ Particulate concentrations $\left(\mathrm{ng} \mathrm{m}^{-3}\right)$} \\
\hline & Min. & Max. & Mean \pm SD & $\mathrm{DF} \%$ & Min. & Max. & Mean \pm SD & $\mathrm{DF} \%$ \\
\hline $\mathrm{ACY}$ & $<$ LOQ & 34.5 & $1.0 \pm 3.0$ & 87 & $<$ LOQ & 1.9 & $7.8 \times 10^{-2} \pm 2.4 \times 10^{-1}$ & 53 \\
\hline ACE & $<\mathrm{LOQ}$ & 3.2 & $0.3 \pm 0.5$ & 90 & $<\mathrm{LOQ}$ & 0.2 & $1.1 \times 10^{-2} \pm 3.1 \times 10^{-2}$ & 22 \\
\hline FLN & $<\mathrm{LOQ}$ & 26.3 & $2.7 \pm 4.0$ & 98 & $<\mathrm{LOQ}$ & 2.5 & $1.1 \times 10^{-1} \pm 3.4 \times 10^{-1}$ & 49 \\
\hline PHE & $<\mathrm{LOQ}$ & 45.0 & $4.7 \pm 5.9$ & 98 & $<\mathrm{LOQ}$ & 14.6 & $0.8 \pm 2.2$ & 72 \\
\hline ANT & $<$ LOQ & 4.7 & $1.3 \times 10^{-1} \pm 4.0 \times 10^{-1}$ & 81 & $<$ LOQ & 1.5 & $6.3 \times 10^{-2} \pm 1.9 \times 10^{-1}$ & 53 \\
\hline FLT & $7.0 \times 10^{-2}$ & 13.8 & $1.3 \pm 1.6$ & 100 & $3.0 \times 10^{-3}$ & 26.1 & $1.3 \pm 3.3$ & 99 \\
\hline PYR & $3.9 \times 10^{-3}$ & 7.7 & $0.6 \pm 0.8$ & 93 & $3.5 \times 10^{-3}$ & 20.7 & $1.1 \pm 2.5$ & 99 \\
\hline BAA & $<$ LOQ & 0.3 & $1.4 \times 10^{-2} \pm 3.7 \times 10^{-2}$ & 38 & $<$ LOQ & 11.1 & $0.5 \pm 1.2$ & 87 \\
\hline CHR & $<\mathrm{LOQ}$ & 0.4 & $6.0 \times 10^{-2} \pm 6.8 \times 10^{-2}$ & 95 & $<\mathrm{LOQ}$ & 15.8 & $0.7 \pm 1.7$ & 97 \\
\hline $\mathrm{BBF}$ & $<\mathrm{LOQ}$ & 0.9 & $1.3 \times 10^{-2} \pm 8.2 \times 10^{-2}$ & 14 & $<\mathrm{LOQ}$ & 13.6 & $0.7 \pm 1.5$ & 96 \\
\hline BKF & $<\mathrm{LOQ}$ & 0.3 & $6.2 \times 10^{-3} \pm 2.6 \times 10^{-2}$ & 4 & $<\mathrm{LOQ}$ & 5.0 & $0.3 \pm 0.6$ & 88 \\
\hline BAP & $<\mathrm{LOQ}$ & 0.5 & $8.7 \times 10^{-3} \pm 4.2 \times 10^{-2}$ & 3 & $<\mathrm{LOQ}$ & 9.1 & $0.4 \pm 0.9$ & 83 \\
\hline IPY & $<\mathrm{LOQ}$ & 0.5 & $7.2 \times 10^{-3} \pm 4.6 \times 10^{-2}$ & 3 & $<\mathrm{LOQ}$ & 10.4 & $0.5 \pm 1.0$ & 81 \\
\hline DHA & & & & 2 & $<\mathrm{LOQ}$ & 1.2 & $4.1 \times 10^{-2} \pm 1.1 \times 10^{-1}$ & 56 \\
\hline $\mathrm{BPE}$ & $<$ LOQ & 0.5 & $7.4 \times 10^{-3} \pm 4.2 \times 10^{-2}$ & 3 & $<\mathrm{LOQ}$ & 6.6 & $0.4 \pm 0.7$ & 90 \\
\hline RET & $6.5 \times 10^{-3}$ & 5.0 & $0.2 \pm 0.4$ & 100 & $<$ LOQ & 4.0 & $0.2 \pm 0.5$ & 73 \\
\hline $\mathrm{BFN}$ & $<$ LOQ & 0.8 & $5.2 \times 10^{-2} \pm 8.2 \times 10^{-2}$ & 80 & $<\mathrm{LOQ}$ & 4.7 & $0.2 \pm 0.5$ & 72 \\
\hline BNT & $<\mathrm{LOQ}$ & $2.1 \times 10^{-2}$ & $2.4 \times 10^{-3} \pm 2.2 \times 10^{-3}$ & 6 & $<\mathrm{LOQ}$ & 0.5 & $2.3 \times 10^{-2} \pm 6.2 \times 10^{-2}$ & 46 \\
\hline BGF & $<\mathrm{LOQ}$ & 0.4 & $5.1 \times 10^{-2} \pm 5.4 \times 10^{-2}$ & 93 & $<\mathrm{LOQ}$ & 7.7 & $0.3 \pm 0.8$ & 92 \\
\hline CPP & $<$ LOQ & 0.2 & $5.0 \times 10^{-3} \pm 2.2 \times 10^{-2}$ & 3 & $<$ LOQ & 10.3 & $0.3 \pm 0.9$ & 73 \\
\hline TPH & $<\mathrm{LOQ}$ & 0.1 & $1.5 \times 10^{-2} \pm 1.5 \times 10^{-2}$ & 87 & $<\mathrm{LOQ}$ & 2.8 & $1.4 \times 10^{-1} \pm 3.2 \times 10^{-1}$ & 86 \\
\hline $\mathrm{BJF}$ & $<\mathrm{LOQ}$ & 0.4 & $8.4 \times 10^{-3} \pm 3.9 \times 10^{-2}$ & 6 & $<$ LOQ & 7.5 & $0.4 \pm 0.9$ & 91 \\
\hline BEP & $<\mathrm{LOQ}$ & 0.5 & $1.0 \times 10^{-2} \pm 4.6 \times 10^{-2}$ & 5 & $<\mathrm{LOQ}$ & 7.2 & $0.4 \pm 0.8$ & 87 \\
\hline PER & & & & 2 & $<\mathrm{LOQ}$ & 1.5 & $6.9 \times 10^{-2} \pm 1.5 \times 10^{-1}$ & 61 \\
\hline DCA & & & & 2 & $<\mathrm{LOQ}$ & 0.6 & $2.9 \times 10^{-2} \pm 6.7 \times 10^{-2}$ & 55 \\
\hline ATT & & & & 2 & $<\mathrm{LOQ}$ & 1.7 & $4.7 \times 10^{-2} \pm 1.5 \times 10^{-1}$ & 48 \\
\hline COR & & & & 2 & $<$ LOQ & 3.3 & $1.3 \times 10^{-1} \pm 3.2 \times 10^{-1}$ & 64 \\
\hline$\sum$ PAHs & 0.6 & 138.6 & $11.3 \pm 15.7$ & & 0.1 & 189.3 & $9.3 \pm 21.2$ & \\
\hline
\end{tabular}

SD: standard deviation; < LOQ: below limit of quantification; $\sum$ PAHs: the sum of the concentrations of individual PAHs with DF > $10 \%$ in either gas or particulate phase. Concentration ranges and means are only reported for analytes with $\mathrm{DF}>2 \%$.

to $485.9 \mathrm{ng} \mathrm{L}-1)$ but noticeably lower than that measured by Holoubek et al. (2007) (i.e., from 2.4 to $6310 \mathrm{ng} \mathrm{L}^{-1}$ ). The concentrations of PCBs and CPs, targeted for analysis in rainwater samples, were <LOQs and, therefore, are not discussed hereafter.

\subsection{Wet deposition fluxes}

$\sum$ PAH daily wet deposition fluxes ranged from < LOQ to $5.5 \times 10^{3}$ (mean \pm SD: $\left.632.9 \pm 900.1\right) \mathrm{ng} \mathrm{m}^{-2}$ (Table 4). $\sum$ PAH seasonal fluxes were noticeably higher during winter and spring compared to summer and autumn (Fig. 1), which is in agreement with previous observations in Europe (Kiss et al., 2001; Škrdlíková et al., 2011). Seasonal changes in SOC fluxes could be due to different factors, such as variations in atmospheric concentrations, precipitation amounts (providing that atmospheric concentrations do not change drastically between seasons), and SOC gasparticle partitioning behavior. The increase in PAH fluxes during winter and spring cannot be explained by changes in precipitation amounts, as indicated in Fig. 1. However, at- mospheric concentrations of PAHs were noticeably higher in winter than they were in other seasons (Fig. 1), in agreement with a previously published study in Europe (Lammel et al., 2011). This may be due to higher emission rate, lower boundary layer mixing height (Birgül et al., 2011), and lower concentrations of $\mathrm{OH}$ radicals in winter (Halsall et al., 2001). This may partly explain the higher fluxes seen during winter periods. Finally, lower temperatures in winter could potentially shift partitioning of the more temperature sensitive SOCs towards particulate phase, and particle scavenging, as opposed to gas scavenging, was suggested to be the dominant wet scavenging mechanism for the removal of PAHs from the atmosphere (Bidleman, 1988; Poster and Baker, 1996; Offenberg and Baker, 2002). In the present study, significant negative regressions were found between near-ground temperature and $\theta$ for a number of PAHs including PYR $\left(r^{2}=0.72, P<0.05, n=150\right)$, FLT $\left(r^{2}=0.69, n=155\right)$, RET $\left(r^{2}=0.75, n=156\right)$, and TPH $\left(r^{2}=0.73, n=162\right)$ (Table S4), which could provide further explanation for higher fluxes during cold seasons. 
Table 2. PCB and CP concentrations and detection frequencies (DF) in air $(n=162)$.

\begin{tabular}{|c|c|c|c|c|c|c|c|c|}
\hline & \multicolumn{4}{|c|}{ Gaseous concentrations $\left(\mathrm{pg} \mathrm{m}^{-3}\right)$} & \multicolumn{4}{|c|}{ Particulate concentrations $\left(\mathrm{pg} \mathrm{m}^{-3}\right)$} \\
\hline & Min. & Max. & Mean \pm SD & DF \% & Min. & Max. & Mean \pm SD & DF $\%$ \\
\hline PCB 28 & $<$ LOQ & 14.3 & $3.2 \pm 2.4$ & 88 & & & & 1 \\
\hline PCB 52 & $<\mathrm{LOQ}$ & 8.4 & $1.5 \pm 1.4$ & 68 & & & & 1 \\
\hline PCB 101 & $<\mathrm{LOQ}$ & 13.9 & $1.2 \pm 1.8$ & 60 & & & & 1 \\
\hline PCB 118 & $<\mathrm{LOQ}$ & 4.0 & $0.3 \pm 0.5$ & 10 & & & & $<\mathrm{LOQ}$ \\
\hline PCB 138 & $<\mathrm{LOQ}$ & 3.9 & $0.5 \pm 0.5$ & 24 & & & & 2 \\
\hline PCB 153 & $<$ LOQ & 8.0 & $1.0 \pm 1.2$ & 62 & $<$ LOQ & 3.1 & $0.3 \pm 0.3$ & 4 \\
\hline PCB 180 & $<\mathrm{LOQ}$ & 2.1 & $0.3 \pm 0.2$ & 14 & $<\mathrm{LOQ}$ & 3.3 & $0.2 \pm 0.3$ & 6 \\
\hline$\alpha-\mathrm{HCH}$ & $<$ LOQ & 44.5 & $4.4 \pm 6.0$ & 57 & & & & 1 \\
\hline$\beta-\mathrm{HCH}$ & & & & 2 & & & & $<\mathrm{LOQ}$ \\
\hline$\gamma-\mathrm{HCH}$ & $<\mathrm{LOQ}$ & 31.4 & $6.6 \pm 6.5$ & 75 & & & & 1 \\
\hline$\delta$-HCH & $<\mathrm{LOQ}$ & 2.0 & $0.4 \pm 0.3$ & 5 & & & & 1 \\
\hline$\varepsilon-\mathrm{HCH}$ & & & & 1 & & & & $<\mathrm{LOQ}$ \\
\hline$o, p^{\prime}-\mathrm{DDE}$ & $<\mathrm{LOQ}$ & 1.9 & $0.4 \pm 0.3$ & 27 & & & & $<\mathrm{LOQ}$ \\
\hline$p, p^{\prime}$-DDE & $<\mathrm{LOQ}$ & 87.3 & $19.5 \pm 15.9$ & 98 & $<\mathrm{LOQ}$ & 6.8 & $0.4 \pm 0.7$ & 31 \\
\hline$o, p^{\prime}-\mathrm{DDD}$ & $<\mathrm{LOQ}$ & 2.2 & $0.3 \pm 0.2$ & 6 & & & & $<\mathrm{LOQ}$ \\
\hline$p, p^{\prime}$-DDD & $<\mathrm{LOQ}$ & 2.4 & $0.4 \pm 0.4$ & 17 & & & & 1 \\
\hline$o, p^{\prime}$-DDT & $<\mathrm{LOQ}$ & 8.9 & $1.5 \pm 1.9$ & 45 & & & & $<\mathrm{LOQ}$ \\
\hline$p, p^{\prime}$-DDT & $<\mathrm{LOQ}$ & 11.2 & $1.6 \pm 2.3$ & 36 & & & & 1 \\
\hline $\mathrm{PeCB}$ & $<\mathrm{LOQ}$ & 52.8 & $9.6 \pm 7.3$ & 99 & & & & 2 \\
\hline $\mathrm{HCB}$ & $<$ LOQ & 279.5 & $86.5 \pm 40.4$ & 99 & $<\mathrm{LOQ}$ & 62.7 & $0.9 \pm 6.2$ & 7 \\
\hline$\sum$ PCBs & $<\mathrm{LOQ}$ & 43.5 & $8.1 \pm 7.2$ & & & & & \\
\hline$\sum \mathrm{HCHs}$ & $<\mathrm{LOQ}$ & 73.8 & $11.0 \pm 11.6$ & & & & & \\
\hline$\sum$ DDTs & $<$ LOQ & 104.3 & $23.2 \pm 19.8$ & & & & & \\
\hline$\sum \mathrm{CBs}$ & $<$ LOQ & 332.3 & $96.1 \pm 42.0$ & & & & & \\
\hline
\end{tabular}

SD: standard deviation; <LOQ: below limit of quantification; $\sum$ PCBs : the sum of the concentrations of PCBs 28, 52, 101, 118, 138,153 , and 180; $\sum$ HCHs: the sum of the concentrations of $\alpha$ - and $\gamma-\mathrm{HCH} ; \sum$ DDTs: the sum of the concentrations of $o, p^{\prime}$-DDE, $p, p^{\prime}$-DDE, $p, p^{\prime}$-DDD, $o, p^{\prime}$-DDT, and $p, p^{\prime}$-DDT; $\sum$ CBs: the sum of the concentrations of PeCB and HCB. Note that only analytes with DF> $10 \%$ in either gas or particulate phase were considered for calculating the sums. Concentration ranges and means are only reported for analytes with DF $>2 \%$.

\subsection{Scavenging ratios}

Scavenging ratios were only determined for those events with air and rainwater sampled from the same air mass $(n=54)$. The rejection criterion was that frontal passage did not occur over the site prior ( $\pm 1 \mathrm{~h}$ uncertainty) to the onset of rain. Out of 54 pair samples, only 32 met the above-mentioned criterion (Table S2) and, hence, $W_{\mathrm{t}}$ ratios were determined for 32 rain events.

The relative importance of gas and particle scavenging can be calculated theoretically using $W_{\mathrm{t}}$ and gas scavenging ratio obtained through the dimensionless Henry's law constant (Offenberg and Baker, 2002; Poster and Baker, 1996). However, this approach was avoided in the present study due to the fact that the equilibrium partitioning of SOCs between gas phase and raindrops, and consequently gas scavenging ratios, is greatly affected by temperature, which may change drastically from cloud to ground level. This process is nonlinear and a representative temperature is unknown. This means that Henry's law constants, which are corrected using ground temperatures, may not necessarily represent the true gas scavenging ratios related to falling raindrops. One should also note that theoretical gas scavenging ratios for SOCs in gas phase, being the inverse of their Henry's law constants, may not entirely reflect the underlying mechanism of the compound removal from the atmosphere. For instance, PAHs with higher vapor pressure normally show higher Henry's law constants, as can be seen from experimental data (Bamford et al., 1999). This would result in relatively lower gas scavenging ratios for gaseous PAHs with higher vapor pressure and solubility.

In the present study, the concentrations of ionic species (i.e., the sum of $\mathrm{SO}_{4}^{2-}$ and $\mathrm{NO}_{3}^{-}$) in $\mathrm{PM}$ and those in adjacent rainwater samples were significantly correlated $(r=$ $0.71, P<0.05, n=23)$. This indicates the efficient removal of PM by rainfall and highlights the importance of particle scavenging in the present study. In general, $W_{\mathrm{t}}$ ratios for individual PAHs ranged from 0 (in cases where concentrations in rainwater were $<\mathrm{LOQ}$ ) to $3.5 \times 10^{5}$, with the exception of FLT for which $W_{\mathrm{t}}$ ranged between $3.7 \times 10^{3}$ and $1.3 \times 10^{6}$ (median: $1.4 \times 10^{4}$ ) (Table 5). Overall, $W_{\mathrm{t}}$ values for relatively more volatile PAHs ( $\log K_{\mathrm{oa}}$ between 6.27 and 7.57), 

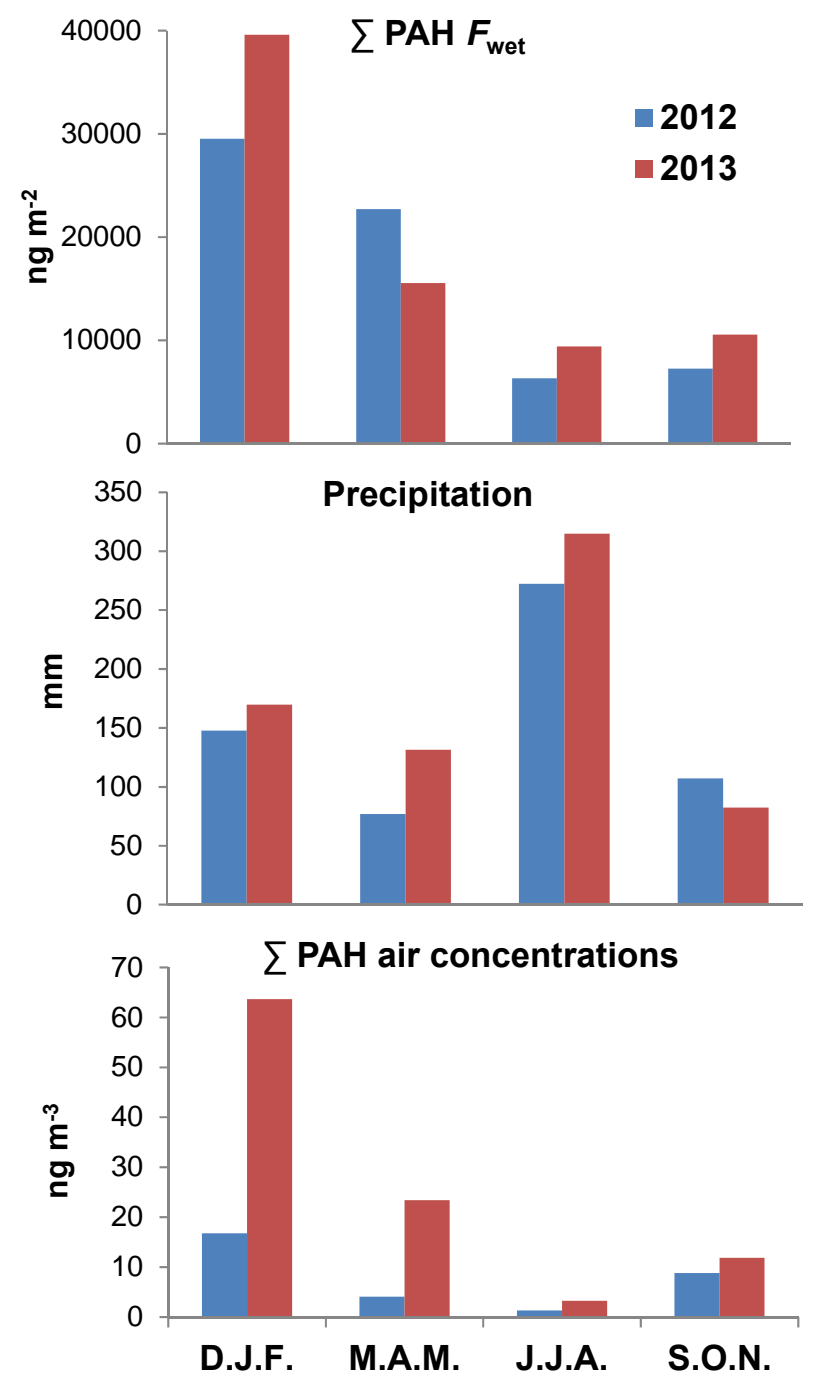

Figure 1. $\sum \mathrm{PAH}$ seasonal fluxes $\left(F_{\text {wet }}\right)$, precipitation amounts, and $\sum$ PAH median air concentrations in winter (D.J.F.), spring (M.A.M.), summer (J.J.A.), and autumn (S.O.N.) at Košetice.

namely ACY, ACE, FLN, ANT, and PHE, were up to $10^{4}$, whereas the values for the rest of PAHs $\left(\log K_{\mathrm{oa}}>8.70\right)$ were up to $10^{6}$, but mainly dominated by the values close to $10^{5}$ (Table 5). Taking into account that SOCs are more efficiently removed from the atmosphere by particle scavenging, the current results may imply that increase in affinity of individual PAHs towards organic phase would overall lead to higher scavenging efficiencies. This, together with other parameters that affect analyte gas-particle partitioning, namely temperature, aerosol surface area and chemical composition (e.g., EC and OC contents) (Junge, 1977; Pankow, 1987; Bidleman, 1988), and factors that affect particle removal rate including rain intensity, aerosol and raindrop size and collision efficiency (Mircea et al., 2000; Poster and Baker, 1996; Slinn et al., 1978), may contribute to the observed variability in measured scavenging ratios.
Table 3. PAH concentrations and detection frequencies (DF) in rainwater $(n=231)$.

\begin{tabular}{|c|c|c|c|c|}
\hline & \multicolumn{4}{|c|}{ Concentrations $\left(\mathrm{ng} \mathrm{L}^{-1}\right.$ ) } \\
\hline & Min. & Max. & Mean \pm SD & DF $\%$ \\
\hline ACY & $<$ LOQ & 23.7 & $2.1 \pm 2.8$ & 67 \\
\hline $\mathrm{ACE}$ & $<\mathrm{LOQ}$ & 7.0 & $1.0 \pm 1.2$ & 54 \\
\hline FLN & $<\mathrm{LOQ}$ & 41.6 & $6.0 \pm 5.8$ & 99 \\
\hline PHE & $<\mathrm{LOQ}$ & 268.0 & $23.5 \pm 29.2$ & 99 \\
\hline ANT & $<\mathrm{LOQ}$ & 41.2 & $1.1 \pm 3.2$ & 56 \\
\hline FLT & $<\mathrm{LOQ}$ & $1.1 \times 10^{3}$ & $61.4 \pm 144.6$ & 99 \\
\hline PYR & $<\mathrm{LOQ}$ & 282.5 & $17.7 \pm 27.0$ & 91 \\
\hline BAA & $<\mathrm{LOQ}$ & 76.9 & $3.1 \pm 6.7$ & 63 \\
\hline CHR & $<\mathrm{LOQ}$ & 141.8 & $9.1 \pm 14.9$ & 75 \\
\hline $\mathrm{BBF}$ & $<\mathrm{LOQ}$ & 85.2 & $6.5 \pm 13.0$ & 69 \\
\hline BKF & $<\mathrm{LOQ}$ & 42.3 & $2.8 \pm 4.8$ & 63 \\
\hline BAP & $<\mathrm{LOQ}$ & 50.0 & $2.3 \pm 4.9$ & 55 \\
\hline IPY & $<\mathrm{LOQ}$ & 58.2 & $3.6 \pm 7.1$ & 60 \\
\hline DHA & $<\mathrm{LOQ}$ & 3.9 & $0.3 \pm 0.4$ & 25 \\
\hline BPE & $<$ LOQ & 50.9 & $3.6 \pm 6.5$ & 59 \\
\hline RET & $<\mathrm{LOQ}$ & 44.0 & $3.1 \pm 4.6$ & 73 \\
\hline BFN & $<\mathrm{LOQ}$ & 67.2 & $3.1 \pm 6.0$ & 62 \\
\hline BNT & $<\mathrm{LOQ}$ & 6.7 & $0.5 \pm 0.7$ & 43 \\
\hline BGF & $<\mathrm{LOQ}$ & 70.8 & $4.9 \pm 7.7$ & 70 \\
\hline СРP & $<\mathrm{LOQ}$ & 17.4 & $1.1 \pm 2.2$ & 48 \\
\hline TPH & $<\mathrm{LOQ}$ & 44.2 & $3.5 \pm 5.4$ & 67 \\
\hline BJF & $<\mathrm{LOQ}$ & 63.0 & $5.6 \pm 9.7$ & 64 \\
\hline BEP & $<\mathrm{LOQ}$ & 60.0 & $4.8 \pm 7.6$ & 73 \\
\hline PER & $<\mathrm{LOQ}$ & 7.8 & $0.5 \pm 0.9$ & 39 \\
\hline DCA & $<\mathrm{LOQ}$ & 7.7 & $0.4 \pm 0.7$ & 27 \\
\hline ATT & $<\mathrm{LOQ}$ & 8.0 & $0.3 \pm 0.7$ & 18 \\
\hline COR & $<\mathrm{LOQ}$ & 22.1 & $1.5 \pm 2.9$ & 52 \\
\hline$\sum$ PAHs & $<\mathrm{LOQ}$ & $2.1 \times 10^{3}$ & $173.3 \pm 256.1$ & \\
\hline
\end{tabular}

SD: standard deviation; <LOQ: below limit of quantification; $\sum$ PAHs: the sum of the concentrations of 27 individual PAHs listed on the table.

Since chlorinated compounds in the present study were mainly detected in gas phase in the air (Table 2), it is likely that their removal from the atmosphere was determined by gas scavenging. The fact that concentrations of these analytes in rainwater were below quantification limits may provide further evidence for this argument, as the magnitude of gas scavenging is negligible.

The upper- and lower-bound scavenged mass fractions of target analytes corresponding to cloud base and top heights were determined for 32 events, except in one case for which cloud top height was not available (Table S2). $\sum$ PAH upper-bound scavenged mass fractions ranged from $1.2 \times 10^{-3}$ to 0.8 (median: $5.3 \times 10^{-2}$ ), whereas lowerbound mass fractions were between $5.2 \times 10^{-4}$ and 0.1 (median: $9.7 \times 10^{-3}$ ) (Table S5). The median ratios for the analyte lower-bound mass fractions were different from those reported by Škrdlíková et al. (2011) for the same site, except for FLN and CHR, which were found to be in agreement (Table S5). This could potentially be related to the relatively 
Table 4. PAH daily wet deposition fluxes $\left(F_{\text {wet }}\right)$.

\begin{tabular}{|c|c|c|c|}
\hline & \multicolumn{3}{|c|}{$F_{\text {wet }}\left(\mathrm{ng} \mathrm{m}^{-2}\right)$} \\
\hline & Min. & Max. & Mean \pm SD \\
\hline $\mathrm{ACY}$ & $<\mathrm{LOQ}$ & 94.8 & $8.4 \pm 14.0$ \\
\hline $\mathrm{ACE}$ & $<\mathrm{LOQ}$ & 76.1 & $4.3 \pm 8.8$ \\
\hline FLN & $<\mathrm{LOQ}$ & 305.3 & $29.8 \pm 43.7$ \\
\hline PHE & $<\mathrm{LOQ}$ & 816.8 & $102.1 \pm 133.1$ \\
\hline ANT & $<$ LOQ & 332.4 & $4.4 \pm 22.6$ \\
\hline FLT & $<\mathrm{LOQ}$ & $4.0 \times 10^{3}$ & $204.1 \pm 413.0$ \\
\hline PYR & $<\mathrm{LOQ}$ & 753.7 & $66.6 \pm 106.0$ \\
\hline BAA & $<\mathrm{LOQ}$ & 182.7 & $10.6 \pm 23.1$ \\
\hline CHR & $<\mathrm{LOQ}$ & 407.5 & $34.0 \pm 60.6$ \\
\hline $\mathrm{BBF}$ & $<\mathrm{LOQ}$ & 569.9 & $21.5 \pm 51.4$ \\
\hline BKF & $<\mathrm{LOQ}$ & 165.7 & $9.8 \pm 19.0$ \\
\hline BAP & $<\mathrm{LOQ}$ & 180.5 & $7.1 \pm 17.9$ \\
\hline IPY & $<\mathrm{LOQ}$ & 178.3 & $12.2 \pm 25.9$ \\
\hline DHA & $<\mathrm{LOQ}$ & 13.5 & $0.6 \pm 1.8$ \\
\hline BPE & $<\mathrm{LOQ}$ & 161.2 & $12.1 \pm 24.5$ \\
\hline RET & $<\mathrm{LOQ}$ & 234.3 & $12.7 \pm 24.3$ \\
\hline $\mathrm{BFN}$ & $<\mathrm{LOQ}$ & 163.5 & $11.6 \pm 23.0$ \\
\hline $\mathrm{BNT}$ & $<$ LOQ & 18.1 & $1.3 \pm 2.7$ \\
\hline BGF & $<\mathrm{LOQ}$ & 240.6 & $18.4 \pm 31.7$ \\
\hline CPP & $<\mathrm{LOQ}$ & 94.5 & $3.4 \pm 9.8$ \\
\hline TPH & $<\mathrm{LOQ}$ & 104.1 & $12.4 \pm 20.0$ \\
\hline $\mathrm{BJF}$ & $<\mathrm{LOQ}$ & 374.2 & $20.6 \pm 43.4$ \\
\hline BEP & $<\mathrm{LOQ}$ & 249.1 & $16.8 \pm 29.8$ \\
\hline PER & $<\mathrm{LOQ}$ & 34.7 & $1.4 \pm 3.6$ \\
\hline DCA & $<\mathrm{LOQ}$ & 16.7 & $0.8 \pm 2.3$ \\
\hline ATT & $<\mathrm{LOQ}$ & 21.3 & $0.7 \pm 2.5$ \\
\hline COR & $<\mathrm{LOQ}$ & 66.5 & $5.0 \pm 10.5$ \\
\hline$\sum$ PAHs & $<\mathrm{LOQ}$ & $5.5 \times 10^{3}$ & $632.9 \pm 900.1$ \\
\hline
\end{tabular}

SD: standard deviation; < LOQ: below limit of quantification.

small number of events considered in that study $(n=10)$. It should be noted that scavenged mass fractions were calculated assuming that analyte concentrations near ground represented those within the air column up to cloud top - i.e., assuming perfect mixing throughout the column. The true scavenged mass fractions could potentially be higher due to a negative vertical concentration gradient (Škrdlíková et al., 2011).

\subsection{Factors affecting the scavenging ratios}

As can be seen from Tables 5 and $\mathrm{S} 3, W_{\mathrm{t}}$ ratios for $\sum$ PAHs in the present study ranged from $2.4 \times 10^{3}$ to $2.3 \times 10^{5}$, with noticeable variability between the events (mean \pm SD: $1.7 \times 10^{4} \pm 3.8 \times 10^{4}$ ). As discussed earlier, different parameters could contribute to the variability seen in scavenging ratios. In this section, we investigate potential relationships between PAH scavenging efficiencies and precipitation intensity, near-ground temperature, the concentrations of $\mathrm{PM}_{2.5}, \mathrm{PM}_{10}$, $\mathrm{PM}$ ionic species (i.e., the sum of the concentrations of $\mathrm{SO}_{4}^{2-}, \mathrm{NO}_{3}^{-}$, and $\mathrm{NH}_{4}^{+}$), $\mathrm{EC}$ and $\mathrm{OC}, \mathrm{PM}$ surface area, and rainwater ionic species (i.e., the sum of $\mathrm{SO}_{4}^{2-}, \mathrm{NO}_{3}^{-}$, and $\mathrm{Cl}^{-}$). As can be seen from Table S3, the highest $\sum$ PAH $W_{\mathrm{t}}$ was found for the samples collected on 14 April 2012. The ratio was nearly 2 orders of magnitude higher compared to that obtained for another event with similar precipitation type and ambient temperature (i.e., 11-12 October 2012). Apart from the concentrations of $\mathrm{PM}_{10}$ and ionic species in PM and rainwater, the rest of the parameters were somewhat similar for these two events (Table S3). The concentrations of $\mathrm{PM}_{10}$ as well as those for ionic species in PM and rainwater for the former event were 1.4, 1.8, and 11 times the values found for the latter event. This observation suggests that PM removal by rain, and consequently wet scavenging of PAHs that are sorbed to PM, is enhanced in conditions where PM contains high quantities of soluble species. This argument is supported by considerably higher scavenging ratios found for particulate PAHs (a factor of 50 on average) in the former event. This difference was much smaller for gaseous species (a factor of 5 on average).

In order to explore the relative importance of the abovementioned parameters in relation to scavenging ratios, correlation analysis was performed between these variables. Among all parameters, aerosol surface area concentration was only available for 2012. In addition, aerosol EC and OC contents could only be obtained for 15 rain events out of 32, as they were recorded once every 6 days (Table S3). Owing to the fact that EC and OC have high importance in SOC gas-particle partitioning (Lohmann and Lammel, 2004), and in order to enhance the comparability of results, for all other parameters, correlation analysis was only performed for the corresponding rain events. The results showed that the concentrations of rainwater ionic species were significantly correlated with $\sum$ PAH scavenging ratios $(r=0.70, P<0.05, n=15)$, whereas weak correlations were found for all other parameters, except the ratio of PM ionic species $/ \mathrm{PM}_{10}$, for which a moderate correlation was found $(r=0.34, P>0.05)$. However, when the data related to 14 April 2012 (with exceptionally high $W_{\mathrm{t}}$ ratio) was excluded from the analysis, the suggested importance of rainwater and PM ionic species decreased $(r=$ 0.14 and 0.07 , respectively, $P>0.05, n=14$ ). This indicates that the initial analysis may have been overpowered by significantly high values of ionic species related to a single event. Without the data point related to 14 April 2012, moderate correlations were obtained between $\sum \mathrm{PAH} W_{\mathrm{t}}$ ratios and $\mathrm{EC} / \mathrm{PM}_{10}(r=0.34, P>0.05)$ and $\mathrm{OC} / \mathrm{PM}_{10}$ $(r=0.39, P>0.05)$. Although not statistically significant, the current results suggest that the aerosol EC and OC contents are important parameters in determining PAH scavenging efficiencies. This may reflect the affinity of PAHs towards EC and OC, representing adsorption and absorption processes (Lohmann and Lammel, 2004). However, the magnitude of these effects could be different when considering individual PAHs. For instance, the coefficients of correlation between $W_{\mathrm{t}}$ and $\mathrm{EC} / \mathrm{PM}_{10}$ ratios for PAHs with mod- 
Table 5. PAH scavenging ratios $\left(W_{\mathrm{t}}\right)$.

\begin{tabular}{|c|c|c|c|c|c|}
\hline & \multicolumn{3}{|c|}{$W_{\mathrm{t}}$} & \multirow[b]{2}{*}{$\log K_{\mathrm{Oa}}$} & \multirow[b]{2}{*}{$\log K_{\text {aw }}$} \\
\hline & Min. & Max. & Median & & \\
\hline ACY & 0 & $6.9 \times 10^{4}$ & $4.7 \times 10^{3}$ & 6.27 & -2.33 \\
\hline ACE & 0 & $3.0 \times 10^{4}$ & $4.5 \times 10^{3}$ & 6.31 & -2.12 \\
\hline FLN & 863.9 & $5.0 \times 10^{4}$ & $4.8 \times 10^{3}$ & 6.79 & -2.41 \\
\hline ANT & 0 & $8.4 \times 10^{4}$ & $2.4 \times 10^{3}$ & 7.55 & -2.64 \\
\hline PHE & $2.2 \times 10^{3}$ & $2.5 \times 10^{4}$ & $5.4 \times 10^{3}$ & 7.57 & -2.76 \\
\hline RET & 0 & $3.2 \times 10^{4}$ & $6.2 \times 10^{3}$ & 8.70 & -2.35 \\
\hline PYR & 0 & $1.1 \times 10^{5}$ & $1.2 \times 10^{4}$ & 8.80 & -3.31 \\
\hline FLT & $3.7 \times 10^{3}$ & $1.3 \times 10^{6}$ & $1.4 \times 10^{4}$ & 8.88 & -3.44 \\
\hline BAA & 0 & $1.5 \times 10^{5}$ & $4.7 \times 10^{3}$ & 9.07 & -3.31 \\
\hline CHR & 0 & $1.6 \times 10^{5}$ & $1.3 \times 10^{4}$ & 9.48 & -3.67 \\
\hline $\mathrm{BFN}$ & 0 & $1.6 \times 10^{5}$ & $8.6 \times 10^{3}$ & 9.57 & -3.80 \\
\hline BGF & 0 & $1.4 \times 10^{5}$ & $1.4 \times 10^{4}$ & 9.78 & -4.26 \\
\hline PER & 0 & $1.5 \times 10^{5}$ & $1.8 \times 10^{3}$ & 10.08 & -3.83 \\
\hline CPP & 0 & $1.8 \times 10^{5}$ & 563 & 10.15 & -4.45 \\
\hline $\mathrm{BBF}$ & 0 & $1.4 \times 10^{5}$ & $7.5 \times 10^{3}$ & 10.35 & -4.57 \\
\hline BJF & 0 & $1.4 \times 10^{5}$ & $9.2 \times 10^{3}$ & 10.59 & -4.48 \\
\hline TPH & 0 & $2.0 \times 10^{5}$ & $1.9 \times 10^{4}$ & 10.69 & -5.20 \\
\hline BKF & 0 & $1.4 \times 10^{5}$ & $5.6 \times 10^{3}$ & 10.73 & -4.62 \\
\hline BAP & 0 & $9.1 \times 10^{4}$ & $1.6 \times 10^{3}$ & 10.86 & -4.73 \\
\hline DCA & 0 & $1.4 \times 10^{5}$ & 0 & 11.11 & -4.70 \\
\hline BEP & 0 & $1.4 \times 10^{5}$ & $1.3 \times 10^{4}$ & 11.35 & -4.91 \\
\hline IPY & 0 & $1.5 \times 10^{5}$ & $7.4 \times 10^{3}$ & 11.55 & -4.85 \\
\hline DHA & 0 & $1.6 \times 10^{5}$ & 0 & 11.78 & -5.24 \\
\hline BPE & 0 & $1.4 \times 10^{5}$ & $6.5 \times 10^{3}$ & 11.97 & -5.27 \\
\hline COR & 0 & $1.8 \times 10^{5}$ & $4.3 \times 10^{3}$ & 13.70 & -6.06 \\
\hline BNT & 0 & $3.5 \times 10^{5}$ & $6.8 \times 10^{3}$ & NA & -4.36 \\
\hline ATT & 0 & $2.3 \times 10^{5}$ & 0 & NA & NA \\
\hline$\sum$ PAHs & $2.4 \times 10^{3}$ & $2.3 \times 10^{5}$ & $8.8 \times 10^{3}$ & & \\
\hline
\end{tabular}

$K_{\mathrm{Oa}}$ : analyte octanol-air partitioning coefficient; $K_{\mathrm{aw}}$ : analyte air-water partitioning coefficient. For ease of interpretation, analytes are sorted based on their $\log K_{\mathrm{Oa}}$ values. $\log K_{\mathrm{Oa}}$ and $\log K_{\mathrm{aw}}$ values were obtained from Estimation Programs Interface Suite 4.11 (USEPA, 2012); zero value indicates an event in which analyte concentration in rainwater was <LOQ; NA: not available.

erate to high particulate mass fractions, namely PYR (mean $\theta=0.40)$, CHR (mean $\theta=0.74)$, and BBF (mean $\theta=0.97$ ), were $0.38,0.20$, and $0.33(n=10)$, whereas the coefficients for correlation with $\mathrm{OC} / \mathrm{PM}_{10}$ ratios were $0.51,0.53$, and 0.03, respectively. Despite not having statistical significance, the results may suggest that the aerosol OC content was more effective than EC for wet scavenging of PYR and CHR. It should be noted that precipitation type (i.e., snow vs. rain) was only available for 8 events out of 15 . These were mainly identified as rainfall (Table S3), which ruled out the potential impact of precipitation type on scavenging efficiencies. The lack of significant linear relationships between scavenging ratios and aerosol and rainwater properties indicates that the process is not controlled by a single factor but rather by a combination of parameters. The findings of the present study highlight the need for incorporating other PM components, such as EC and OC, in air pollution models for more accurate estimation of particulate $\mathrm{PAH}$ scavenging.

\section{Conclusions}

The results suggest that volatilization from contaminated soil was the main source of chlorinated compounds in the air over Košetice. Higher $\sum$ PAH fluxes in winter were possibly related to higher PAH atmospheric concentrations and particulate mass fractions in that season. Particle scavenging was found to be significant in the present study, as indicated by the strong correlation between rainwater and PM ionic species. In sum, greater scavenging ratios were found for less volatile PAHs, highlighting the importance of SOC gas-particle partitioning in determining their scavenging efficiencies. The results suggested that PM removal by rain, and consequently wet scavenging of PAHs sorbed to PM, could 
be more efficient in cases where the concentrations of ionic species in PM are high. In addition, the high affinity of PAHs towards EC and OC were found to be reflected in the scavenging efficiency. In most model applications which study PAHs, particulates are scavenged either as in conventional air pollution modeling - i.e., accounting for PM ionic composition, but no other PM components (parameterization based on Köhler theory or empirical approaches based on cloud droplet number) (Abdul-Razzak and Ghan, 2000; Gong et al., 2003) - or with insoluble aerosols or aerosol modes (Sehili and Lammel, 2007; Friedman and Selin, 2012). Future studies would need to focus on in-depth analysis of PM chemical composition with the aim to include OC and EC in the parameterizations of particulate $\mathrm{PAH}$ wet deposition.

\section{The Supplement related to this article is available online at doi:10.5194/acp-15-1795-2015-supplement.}

Acknowledgements. We thank Miroslava Bittová and Jan Kuta (Masaryk University) for ion analyses, Jaroslav Pekarek (CHMI) for providing meteorological data, and Vladimir Zdimal (Institute for Chemical Process Fundamentals, the Academy of Sciences of the Czech Republic) for providing aerosol number-size distribution data. This research was supported by the Granting Agency of the Czech Republic (GACR project no. P503/11/1230) and has been cofunded by the European Social Fund and the state budget of the Czech Republic. The research infrastructure (i.e., RECETOX) has been supported by the Czech Ministry of Education (LO1214 and LM2011028).

The service charges for this open access publication have been covered by the Max Planck Society.

Edited by: B. Ervens

\section{References}

Abdul-Razzak, H. and Ghan, S. J.: A parameterization of aerosol activation 2. Multiple aerosol types, J. Geophys. Res.-Atmos., 105, 6837-6844, 2000.

Agrell, C., Larsson, P., Okla, L., and Agrell, J.: PCB congeners in precipitation, wash out ratios and depositional fluxes within the Baltic Sea region, Europe, Atmos. Environ., 36, 371-383, 2002.

Atlas, E. and Giam, C. S.: Ambient concentration and precipitation scavenging of atmospheric organic pollutants, Water Air Soil Pollut., 38, 19-36, 1988.

Bamford, H. A., Poster, D. L., and Baker, J. E.: Temperature dependence of Henry's law constants of thirteen polycyclic aromatic hydrocarbons between $4{ }^{\circ} \mathrm{C}$ and $31^{\circ} \mathrm{C}$, Environ. Toxicol. Chem., 18, 1905-1912, 1999.

Bidleman, T. F.: Atmospheric processes, Environ. Sci. Technol., 22, 361-367, 1988.
Birgül, A., Tasdemir, Y., and Cindoruk, S. S.: Atmospheric wet and dry deposition of polycyclic aromatic hydrocarbons (PAHs) determined using a modified sampler, Atmos. Res., 101, 341-353, 2011.

Blais, J. M.: Biogeochemistry of persistent bioaccumulative toxicants: Processes affecting the transport of contaminants to remote areas, Can. J. Fish. Aquat. Sci., 62, 236-243, 2005.

BWK: Verein Berliner Wetterkarte, e.V. (Ed.), www. berliner-wetterkarte.de (last access: 16 February 2014), 2013.

Dvorská, A., Lammel, G., Klánová, J., and Holoubek, I.: Košetice, Czech Republic - ten years of air pollution monitoring and four years of evaluating the origin of persistent organic pollutants, Environ. Pollut., 156, 403-408, 2008.

Dvorská, A., Lammel, G., and Holoubek, I.: Recent trends of persistent organic pollutants in air in central Europe - Air monitoring in combination with air mass trajectory statistics as a tool to study the effectivity of regional chemical policy, Atmos. Environ., 43, 1280-1287, 2009.

EPER: European Pollutant Emission Register, http://www.eea.europa.eu/data-and-maps/data/ eper-the-european-pollutant-emission-register-4 (last access: 4 March 2014), 2014.

Friedman, C. L. and Selin, N. E.: Long-range atmospheric transport of polycyclic aromatic hydrocarbons: A global 3-D model analysis including evaluation of arctic sources, Environ. Sci. Technol., 46, 9501-9510, 2012.

Gioia, R., Sweetman, A. J., and Jones, K. C.: Coupling passive air sampling with emission estimates and chemical fate modeling for persistent organic pollutants (POPs): A feasibility study for northern Europe, Environ. Sci. Technol., 41, 2165-2171, 2007.

Gong, S. L., Barrie, L. A., Blanchet, J. P., von Salzen, K., Lohmann, U., Lesins, G., Spacek, L., Zhang, L. M., Girard, E., Lin, H., Leaitch, R., Leighton, H., Chylek, P., and Huang, P.: Canadian Aerosol Module: A size-segregated simulation of atmospheric aerosol processes for climate and air quality models 1 . Module development, J. Geophys. Res.-Atmos., 108, AAC 3-1-AAC 3$16,2003$.

Grimalt, J. O., Fernandez, P., Berdie, L., Vilanova, R. M., Catalan, J., Psenner, R., Hofer, R., Appleby, P. G., Rosseland, B. O., Lien, L., Massabuau, J. C., and Battarbee, R. W.: Selective trapping of organochlorine compounds in mountain lakes of temperate areas, Environ. Sci. Technol., 35, 2690-2697, 2001.

Hageman, K. J., Simonich, S. L., Campbell, D. H., Wilson, G. R., and Landers, D. H.: Atmospheric deposition of current-use and historic-use pesticides in snow at National Parks in the Western United States, Environ. Sci. Technol., 40, 3174-3180, 2006.

Halsall, C. J., Sweetman, A. J., Barrie, L. A., and Jones, K. C.: Modelling the behaviour of PAHs during atmospheric transport from the UK to the Arctic, Atmos. Environ., 35, 255-267, 2001.

Halse, A. K., Schlabach, M., Eckhardt, S., Sweetman, A., Jones, K. C., and Breivik, K.: Spatial variability of POPs in European background air, Atmos. Chem. Phys., 11, 1549-1564, doi:10.5194/acp-11-1549-2011, 2011.

Holoubek, I., Klánová, J., Jarkovský, J., and Kohoutek, J.: Trends in background levels of persistent organic pollutants at Kosetice observatory, Czech Republic. Part I. Ambient air and wet deposition 1996-2005, J. Environ. Monit., 9, 557-563, 2007. 
IGRA: Integrated Global Radiosonde Archive, ftp://ftp.ncdc.noaa. gov/pub/data/igra (last access: 23 February 2014), 2014.

Junge, C. E.: Fate of Pollutants in the Air and Water Environments, edited by: Suffett, I. H., John Wiley and Sons, New York, 7-25, 1977.

Kaupp, H. and McLachlan, M. S.: Distribution of polychlorinated dibenzo-P-dioxins and dibenzofurans (PCDD/Fs) and polycyclic aromatic hydrocarbons (PAHs) within the full size range of atmospheric particles, Atmos. Environ., 34, 73-83, 2000.

Kiss, G., Varga-Puchony, Z., Tolnai, B., Varga, B., Gelencsér, A., Krivácsy, Z., and Hlavay, J.: The seasonal changes in the concentration of polycyclic aromatic hydrocarbons in precipitation and aerosol near Lake Balaton, Hungary, Environ. Pollut., 114, 55-61, 2001.

Lammel, G., Novák, J., Landlová, L., Dvorská, A., Klánová, J., Čupr, P., Kohoutek, J., Reimer, E., and Škrdlíková, L.: Sources and Distributions of Polycyclic Aromatic Hydrocarbons and Toxicity of Polluted Atmosphere Aerosols, in: Urban Airborne Particulate Matter, edited by: Zereini, F. and Wiseman, C. L. S., Environmental Science and Engineering, Springer Berlin Heidelberg, 39-62, 2011.

Ligocki, M. P., Leuenberger, C., and Pankow, J. F.: Trace organic compounds in rain. III. Particle scavenging of neutral organic compounds, Atmos. Environ., 19, 1619-1626, 1985.

Liu, F., Xu, Y., Liu, J., Liu, D., Li, J., Zhang, G., Li, X., Zou, S., and Lai, S.: Atmospheric deposition of polycyclic aromatic hydrocarbons (PAHs) to a coastal site of Hong Kong, South China, Atmos. Environ., 69, 265-272, 2013.

Lohmann, R. and Lammel, G.: Adsorptive and Absorptive Contributions to the Gas-Particle Partitioning of Polycyclic Aromatic Hydrocarbons: State of Knowledge and Recommended Parametrization for Modeling, Environ. Sci. Technol., 38, 3793 3803, 2004.

McLachlan, M. S. and Sellström, U.: Precipitation scavenging of particle-bound contaminants - A case study of PCDD/Fs, Atmos. Environ., 43, 6084-6090, 2009.

Mircea, M., Stefan, S., and Fuzzi, S.: Precipitation scavenging coefficient: influence of measured aerosol and raindrop size distributions, Atmos. Environ., 34, 5169-5174, 2000.

Offenberg, J. H. and Baker, J. E.: Precipitation Scavenging of Polychlorinated Biphenyls and Polycyclic Aromatic Hydrocarbons along an Urban to Over-water Transect, Environ. Sci. Technol., 36, 3763-3771, 2002.
Pankow, J. F.: Review and comparative analysis of the theories on partitioning between the gas and aerosol particulate phases in the atmosphere, Atmos. Environ., 21, 2275-2283, 1987.

Poster, D. L. and Baker, J. E.: Influence of Submicron Particles on Hydrophobic Organic Contaminants in Precipitation. 2. Scavenging of Polycyclic Aromatic Hydrocarbons by Rain, Environ. Sci Technol., 30, 349-354, 1996.

Roots, O., Roose, A., Kull, A., Holoubek, I., Čupr, P., and Klánová, J.: Distribution pattern of PCBs, HCB and PeCB using passive air and soil sampling in Estonia, Environ. Sci. Pollut. Res., 17, 740-749, 2010.

Sehili, A. M. and Lammel, G.: Global fate and distribution of polycyclic aromatic hydrocarbons emitted from Europe and Russia, Atmos. Environ., 41, 8301-8315, 2007.

Škrdlíková, L., Landlová, L., Klánová, J., and Lammel, G.: Wet deposition and scavenging efficiency of gaseous and particulate phase polycyclic aromatic compounds at a central European suburban site, Atmos. Environ., 45, 4305-4312, 2011.

Slinn, W. G. N., Hasse, L., Hicks, B. B., Hogan, A. W., Lal, D., Liss, P. S., Munnich, K. O., Sehmel, G. A., and Vittori, O.: Some aspects of the transfer of atmospheric trace constituents past the air-sea interface, Atmos. Environ., 12, 2055-2087, 1978.

USEPA: United States Environmental Protection Agency, Estimation Programs Interface Suite ${ }^{\mathrm{TM}}$ for Microsoft ${ }^{\circledR}$ Windows, v 4.11, United States Environmental Protection Agency, Washington, DC, USA, 2012.

van Ry, D. A., Gigliotti, C. L., Glenn, Nelson, E. D., Totten, L. A., and Eisenreich, S. J.: Wet Deposition of Polychlorinated Biphenyls in Urban and Background Areas of the Mid-Atlantic States, Environ. Sci. Technol., 36, 3201-3209, 2002.

Wiman, B. L. B., Unsworth, M. H., Lindberg, S. E., Bergkvist, B., Jaenicke, R., and Hansson, H. C.: Perspectives on aerosol deposition to natural surfaces: interactions between aerosol residence times, removal processes, the biosphere and global environmental change, J. Aerosol Sci., 21, 313-338, 1990.

Yolsal, D., Salihoglu, G., and Tasdemir, Y.: Air-soil exchange of PCBs: Levels and temporal variations at two sites in Turkey, Environ. Sci. Pollut. Res., 21, 3920-3935, 2014. 